\title{
РОЛЬ КИТАЯ В ЭКОНОМИЧЕСКОМ РАЗВИТИИ ДАЛЬНЕГО ВОСТОКА РОССИИ В ПЕРИОД С 1858 ПО 1917 ГГ.1
}

\section{THE ROLE OF CHINA IN THE ECONOMIC DEVELOPMENT OF THE RUSSIAN FAR EAST IN THE PERIOD FROM 1858 TO 1917 \\ Fu Xuejing \\ Ning Yanhong}

Summary: The article presents the results of a study aimed at establishing the significance of Russian state policy and the role of Chinese citizens in the economic development of the Russian territories of the Far East. In the course of the study, the historical period of development and economic development of the Russian territories bordering China from 1858 to 1917 was studied by means of a retrospective analysis. The results of the study allowed us to identify a number of stages in the development of the Far East, the characteristics of which are due to changes in the immigration policy of Russia, and to establish the role of Chinese citizens in the sustainable economic development of Russian border areas.

Keywords: Russia, China, the far East, emigration policy, economic development.

\author{
Фу Сюецзин \\ Библиотекарь, Хэйхэский университет, \\ провинция Хэйлунцияна, КНР \\ 445886690@q9.com \\ Нин Яньхун \\ С.н.С., Хэйхэский университет, \\ провинция Хэйлунцияна, КНР \\ 278906744@q9.com
}

Аннотация: В статье представлены результаты исследования, целью которого стало установление значения государственной политики России и роли граждан Китая в экономическом развитии российских территорий Дальнего Востока. В ходе исследования посредством ретроспективного анализа был изучен исторический период освоения и экономического развития приграничных с Китаем российских территорий начиная с 1858 по 1917 годы. Результаты исследования позволили выделить ряд этапов развития Дальнего Востока, характеристики которых обусловлены изменениями иммиграционной политики России, и установить роль граждан Китая в устойчивом экономическом развитии российских приграничных районов.

Ключевые слова: Россия, Китай, Дальний Восток, эмиграционная политика, экономическое развитие.

отражение в иммиграционной политике Дальнего Востока и экономическом развитии двух государств в различные исторические периоды становления двух стран Китая и России.

\section{Теоретическое обоснование проблемы исследования}

в соответствии с которыми Россия получила суверенитет над более чем 1,5 млн. км² земли на Дальнем Востоке. Основанием для подписания указанных договоров стало понимание России потребности в приобретении новых территорий с целью увеличения населения и повышения её плотности, что благоприятным образом отразиться на развитии Дальнего Востока.

Произошедшие в последующем изменения, обусловленные консолидированным режимом на Дальнем Востоке и предпринятыми российским правительством в рамках названных договоров мер по развитию сельского хозяйства, ремесел, транспорта, городского строительства и инвестиций в строительство ряда крупных инженерных проектов. что в совокупности нашло своё
С целью наиболее полного раскрытия темы исследования и достижения его цели, первоначально обратимся к поэтапному рассмотрению ряда важных, с нашей точки зрения, вопросов, первым из которых является установление причин эмиграции граждан Китая в Россию, которая обусловлена как внутренними, так и внешними факторами. Среди всех предполагаемых причин эмиграции в ходе анализа нами выделены следующие: первая социальные изменения в Китае, вторая - благоприятные условия, предоставленные периодом «открытого пути», третья - освоение российский территорий Дальнего Востока. Остановимся более подробно на каждой из названных причин.

Данная статья является результатом научно-исследовательского проекта 2019 г. провинциальных вузов Хэйлунцзяна «Исследование архивных материалов о китайцах в Сибири и на Дальнем Востоке России в конце династии Цин и начала Китайской Республики». Номер проекта: 2019-KYYWF-0479, и проекта 2019 г. Ассоциации китайских эмигрантов «Исследование о жизни китайцев на Дальнем Востоке России». 
Подписание двустороннего межгосударственного Пекинского договора 1860 г., между Россией и империей Цин, как продолжение Айгунского и Тяньцзинского договоров, устранило препятствие со стороны правительства Китая на выезд своих граждан за границу с целью трудоустройства [11, с.145], таким образом продемонстрировав отказ правительства Цин от политики, запрещающей китайцам пересекать границу государства. Стоит подчеркнуть, что легализация китайцев, выезжающих за границу, их число на территории России существенно увеличилось. Кроме отмеченного, необходимо указать на ещё ряд факторов, послуживших своеобразным толчком к увеличению беженцев на Северо-Востоке страны с целью поиска работы, а именно, последствия Опиумной войны, коррупции и некомпетентности правительства Цин, внутреннего милитаризма и стихийных бедствий (провинция Хэбэй, Шаньдун и др.): наводнения, засухи и насекомые-вредители, что привели к потери китайскими крестьянами своих земель.

Создание благоприятных условий в период «открытого пути» для эмиграции граждан Китая в Россию, обусловлено подписанием «Айгуньского договора» 1858 г. предусматривающего примирение народов двух стран и поддержки со стороны чиновников торговли с обеих сторон на территории границ рек Уссури, Амура и Сунгари. В названном договоре предусматривается возможность осуществления торговых операций (трансграничная торговля) «на перекрестке» двух стран без уплаты налогов.

Согласно сохранившимся записям поселка Айгунь, в Благовещенск были приглашены китайские купцы с целью налаживания торговли между двумя странами, для чего были возведены склады для охранения товаров. Каждый день в 10 часов утра китайские торговцы, переправлялись через реку в г. Благовещенск, осуществляли торговлю, а в 16 часов возвращались на территорию Китайской Народной Республики (далее - КНР). Несколько позже, российская сторона разрешила китайским предпринимателям самостоятельно выбирать места для торговли в г. Благовещенске, открывать свои предприятия, численность которых достигла порядка 500 объектов, импортировать зерно и предметы первой необходимости на российскую территорию Дальнего Востока. Развитию торговли способствовали и некоторые географические условия, в частности, наличие ряда больших и малых островов, расположенных от уезда Хума в верховьях Амура до уезда Суньу в среднем течении Амура на границе между Китаем и Россией (о-в Цзянбаохэ, восточные о-ва Сюйшэн, о-в Синлун) на расстоянии десятков метров от китайского берега, позволяющих достаточно быстро достичь территории России. Созданный таким образом торговый трафик позволил в кратчайшие сроки наладить китайско-российскую торговлю и привести её к процветанию, а данный период получил название «от- крытый транспорт».

Освоению гражданами КНР российской территории Дальнего Востока способствовал спрос на рабочую силу с целью экономического развития российского Дальнего Востока. В частности, рабочая сила требовалась при запуске серии крупных инженерных сооружений (1860 г.), созданных в соответствии с политической и экономической стратегии России. Использование российских работников на подобных объектах требовало значительных временных затрат, а ухудшение условий жизни в Китае способствовало принятию экономически взаимовыгодного решения по найму работников из соседней дружественной страны.

Так, согласно отчету Китайского общества в России, в декабре 1917 г. «численность китайских рабочих с лета прошлого года до сего времени уже превысило 100000 тыс. чел.» [10, с.191]. В отчетах отмечается, что за годы Первой мировой войны общее количество китайских рабочих и бизнесменов, в районе Хэйлунцзян, достигло 502621 тыс. чел. Так, в период 1913-1918 гг. ежегодно среднее число граждан КНР, посетивших Россию, составляло 83770 тыс. чел. [8]. Кроме провинции Хэйлунцзян, своеобразным эмиграционным коридором выступали провинции Шаньдун, Хэбэй, Ляонин, Цзилинь, Хэйхэ и Лужи, что в итоге, позволило создать Ассоциацию китайско-российских региональных торговых союзов (округ ХэйХэ).

Определив причины эмиграции граждан Китая в Россию, далее, обратимся к рассмотрению российской иммиграционной политики по отношению к гражданам Китая, обозначив несколько исторически обусловленных периодов.

Первый период (с. 1858 по 1880 гг.) получил название мягкой иммиграчионной политики, в ходе которого Россия привлекала население страны (внутренняя миграция) и граждан Китая (внешняя эмиграция) для расселения на российской территории Дальнего Востока с целью увеличения плотности населения. Внутренняя миграция осуществлялась посредством переселения семей специально набранной в 1857 г. российским губернатором Восточной Сибири Н.Н. Муравьевым казачьей армии, в деревня, расположенные вдоль реки Амур. Однако несмотря на то, что уже к 1861 г. насчитывалось около 60 новообразованных деревень общей численностью 11850 тыс. жителей, процесс переселения происходил крайне медленно в виду многочисленных ограничений $[2$, c.2]. С целью привлечения большего числа людей для расселения в Амурской и Приморской областях, 27 апреля 1861 г. было разработано «Положение о миграции русских и иностранцев в Амурскую и Приморскую области» (далее - Положение), для активизации переселения на территориях Дальнего Востока. Согласно По- 
ложению, предусматривалось добровольное поселение российских и иностранных граждан с предоставлением бесплатных земель с правом временного или постоянного владения ими в качестве частной собственности (при оплате за каждую десятину три рубля) [1, с.64-65]. Предпринятые Россией льготные меры привлекли местных и иностранных граждан для переселения в Амурскую и Приморскую области Дальнего Востока, что в определенной степени стимулировало китайскую эмиграцию. Согласно сохранившемуся документу «Провинциальное краеведение Цзилинь. Отчет о политических делах XI часть», начиная с 1862 г. ежегодно порядка 1000 граждан Китая пересекали реки Хэйлунцзян и Уссури в области Амурской и Приморской областях. По данным, предоставленным экспертом в области пограничной истории и географии Цао Тинцзе, в 1885 г. число граждан Китая на Дальнем Востоке России составляло примерно 28 тыс. чел. во г. Владивостоке, 8 тыс. чел. в г. Уссурийске, 2 тыс. чел. в г. Хабаровске, 2 тыс. чел. в г. Благовещенске и 20 тыс. чел. на восточном берегу реки Уссури и в прибрежной зоне [4, с.72].

Второй период - период ограничения иммиграционной политики, ознаменован принятием российского правительства ряда ограничений на въезд иностранных граждан на территорию Дальнего Востока и отменой первоначально придерживаемой специальной политикой по отношению к иностранным иммигрантам. В 1882 г. условия о переселении на территорию Дальнего Востока иностранных граждан оставались прежними, однако льготными привилегиями могли пользоваться только граждане России, и лишь в исключительных случаях могли быть предоставлены гражданам Китая. В 1892 г. российским правительством было вновь пересмотрена эмиграционная политика, в результате чего внесены поправки ужесточающие требования, предъявляемые к иностранным гражданам, в частности, отказ в предоставлении им возможности покупки земель на территории Амурской и Приморской областей [5, с.68], что снизило поток китайских эмигрантов.

В рассматриваемый исторический период со стороны российского правительства были приняты ряд мер, которые выступили в качестве регулирующих механизмов российско-китайских взаимоотношений. В частности, с одобрения представителей местного полицейского участка, стало возможным назначение ответственного за эмиграционных процессы граждан Китая в обязанности которого входил контроль за прибывающими на место постоянного проживания на территории России иностранных граждан, получения ими необходимой визы на жительство и транзит, наличия национального паспорта. В связи со сказанным в 1906 г. китайским дипломатом и политиком Ху Вэйдэ были разработаны «Паспортные правила для китайцев за границей», согласно которым в паспорте размещалась отметка о профессиональной де- ятельности потенциального эмигранта [5, с.75]. При необходимости найма на работу иностранца российской компанией, её представители должны были осуществить предварительные переговоры, в ходе которых осуществлялась проверка паспорта и определялось конкретное место работы, что исключало возможность самостоятельного выбора со стороны работника. Устанавливался конкретный срок (один месяц) прибывания иностранного работника на территории России, по истечению которого должна оформляться виза на жительство в соответствии с правилами, стоимость которой составляла 5 руб. Следует отметить, что в период с 1895 по 1897 гг. средний годовой доход иностранных работников за достигал 63518 тыс. руб. [9, с.18].

К 1910 г. более 40 тыс. китайских рабочих осуществляли свою профессиональную деятельность на государственных и частных предприятиях в Амурской и Приморской областях, что составляло около 70 \% от общего количества специалистов, задействованных в различных сферах и отраслях народного хозяйства: золотодобывающей, лесозаготовительной, дорожно-строительной, сельскохозяйственной, обслуживающей, розничной и др. Начиная с 1910 г. российское правительство наложило запрет на привлечение иностранных граждан к профессиональной деятельности на территории России, исключая те случае, когда необходимо было выполнение срочных работ при недостаточной численности российских граждан для их выполнения.

И, наконец, третий период, характеризующийся массовым набором китайских рабочих, пришедший на смену предыдущего, в связи с началом Первой мировой войны 1914 г., вынудившей Россию отказаться от ранее обнародованной политики, запрещающей китайским специалистам осуществлять своё профессиональную деятельность на территории Дальнего Востока. Уже в 1915 г. были изданы временные правила найма китайских рабочих, введена соответствующая ситуации льготная политика, несколько позднее приняты постоянные правила найма на работу китайских граждан. Согласно данным архивных материалов, сохранившихся в канцелярии губернатора провинции Цзилинь Китая (1917 г.), в рассматриваемый исторический период была аннулирована национальная лицензия и введён в документальный оборот специальный паспортный билет, позволяющий гражданам Китая осуществлять свою профессиональную деятельность в особо значимых для России отраслях народного хозяйства.

Данный период характеризуется тенденцией к активизации вербовочной компании, направленной на привлечение китайских специалистов к стратегически важным сферам деятельности, как в государственном, так и в частном секторах. Так, в 1915 г. Харбинский Муниципальный комбинат «Дуншэн» в провинции Фэнтяне, 
принадлежащий русским купцам, набрал 8000 тыс. чел., представитель китайской компании «Хуаъи» Чжоу Мянь подписал контракт с русской компанией на предоставление 20 тыс. рабочих мест для китайских специалистов, главный инженер Русско-арабского завода И.А. Семенов поручил Хе Гоучжуну завербовать порядка 1203 тыс. граждан Китая для работ в провинции Фэнтяне, а русскими представителями были подписаны контракты с Ван Тунвэнем и Ян Суном в городах Цзилине, Шуанчэне и Харбине на набор китайских рабочих в размере 1000 тыс. чел. [8]. В марте 1916 года в газете «Дальневосточные новости», опубликованной администрацией Ближневосточной железной дороги в Харбине, было объявлено о наборе 2200 тыс. китайских рабочих для строительства железной дороги Томской области [4, с.124]. С 1916 по 1917 гг. порядка 5200 китайских рабочих прошли «инспекцию» Российским управлением по надзору в сфере здравоохранения в уезде Гусянтуне при городе Харбине, что позволило им приступить к реализации на территории Дальнего Востока своей профессиональной деятельности [9, с.110]. Таким образом, рассмотренный нами исторический этап становления российско-китайских отношений характеризуется масштабными эмиграционными процессами граждан Китая не только на российской территории Дальнего Востока, но и по всему Сибирскому региону.

Далее, в настоящем исследовании мы обратимся к ретроспективному анализу оказанного гражданами Китая влияния на экономическое развитие российского Дальнего Востока, отмечая их обширное расселение в районах г. Благовещенска, г. Хабаровска, г. Владивостока и г. Уссурийска.

Иммиграционные правила, принятые Россией в 1861 г., предусматривали достаточную степень свободы эмигрантам, занятым в сельском хозяйстве, что было обусловлено наличием у них знаний климатических условий Дальнего Востока и большого опыта ведения сельского хозяйства [3, с.26]. Таким образом, граждане Китая смогли привнести многолетний накопленный опыт ведения сельского хозяйства в Россию, обучая российских специалистов китайскому методу выращивания сельскохозяйственных продуктов питания и разрабатывая новые технологии их обработки, что нашло своё позитивное отражение на сельскохозяйственном производстве Дальнего Востока в целом. Кроме того, благодаря гражданам Китая, задействованным в сельском хозяйстве приграничных российско-китайских территорий, было освоена большая площадь обрабатываемых земель вблизи русской резиденции вдоль реки Уссури, что позволило не только удовлетворить потребности в продуктах питания местного населения, но и обеспечить их экспорт по всей территории Дальнего Востока. Согласно статистическим данным, к 1885 г. гражданами Китая было освоено около 100000 тыс. акров российской земли [12].
Китайские рабочие составили одну из самых многочисленных групп иностранных эмигрантов в России, объединяющую в себе рабочих, имеющих разрешение на долгосрочное проживание на российских территориях, сезонных рабочих, а также специалистов, занимающихся рыболовством, охотой, сбором урожая, добычей золота, лесозаготовкой, строительством железных дорог, морскими и грузовыми перевозками, городским строительством, предоставлением услуг местного населению и т.д. Так, согласно сохранившемуся отчёту округа Хэйлунцзян, десятки тысяч китайских рабочих были задействованы в лесозаготовке и добыче золота, объём которого составил порядка $85,7 \%$ от общего. В российских городах китайские рабочие составляли относительно высокую долю во всех сферах жизнедеятельности человека, так, согласно данным, представленным официальной российской статистикой, в 1910 г. более 50 тыс. иностранных граждан (95\%) были заняты на золотых приисках, строительстве и обслуживании Уссурийской и Амурской железной дорогах, в транспортном бюро, военном департаменте, иммиграционном бюро, отделе почты и телекоммуникаций, в министерстве промышленности и торговли, кирпичных, пивоваренных и спичечных заводах, ряде государственных агентств и частных предприятий, занимающихся добычей золота, погрузкой, разгрузкой и транспортировкой судов, машиностроением, лесным хозяйством и других хозяйственных отраслях.

В национальных учреждениях и предприятиях Амурской области насчитывалось около 37373 тыс. граждан России и 2405 тыс. граждан Китая, а на частных предприятиях - 2962 тыс. и 10705 тыс. соответственно. Общее число рабочих-граждан России в Приморской области составляло 23938 тыс. чел., а граждан Китая - 23171 тыс. чел., т.е. около 50\% от общего числа рабочих. Таким образом, можно заключить, что приток большого количества рабочих-граждан Китая способствовал быстрым темпам экономического развития на Дальнем Востоке.

После подписания «Пекинского договора» между Китаем и Россией китайские бизнесмены стали активно осуществлять предпринимательскую деятельность в приграничных районах Дальнего Востока. Из-за небольшого числа местного населения, пополняемого в основном за счет переселенцев с других районов России, экономическая производительность продовольствия и предметов первой необходимости оставалась на достаточно низком уровне, а поставляемые из Европы товары в виду существенных транспортных затрат реализовывались по достаточно высокой цене. Совокупность вышеназванных сложившихся условий выступала в роли благоприятной предпосылки для развития коммерческой деятельности гражданами Китая на Дальнем Востоке. 
Первоначально, коммерческая деятельность Китая с Россией началась с оборота алкоголя. Опираясь на данные, представленные в книге «История китайско-советской экономики и торговли», в 1880-х гг. китайскими бизнесменами ежегодно доставлялось из уездов Айгуня и Хэйхэ в Россию около 50 000-60 000 тыс. пудов шнапса. Несколько позже стала развиваться торговля зерном, тканью и другими предметами первой необходимости. В правительственных архивах династии Цин сохранились документы, свидетельствующие о том, что в 1881 г. во Владивостоке насчитывалось около 6-7 тыс. граждан Китая, из которых порядка 70-80\% были заняты коммерческой деятельностью. Так, к концу династии Цин в приграничной зоне России, в частности, в г. Благовещенске насчитывалось более 10 тыс. граждан Китая, и более 500 принадлежащих им коммерческих предприятий, 12 из которых с капиталом от 3000 до 5000 тыс. рублей. Кроме крупных коммерческих предприятий, практически повсюду велась «мелкая» торговля, осуществляли свою деятельность небольшие ремесленные мастерские (универмаги, магазины готовой одежды, шляпные магазины, пекарни, кондитерские и т.д.), созданные гражданами Китая [8].

\section{Результаты исследования}

Таким образом, резюмируя результаты исследования, полученные в ходе ретроспективного анализа представленных в различных информационных источниках данных, можно заключить, что начиная с 1858 по 1917 гг. эмиграционная политика России претерпевала значительные трансформации, что было обусловлено рядом внешних и внутренних факторов (политических, экономических, социальных), позволившей выделить в ней несколько исторических этапов становления российско-китайских взаимоотношений. Каждый из представленных в исследовании этапов характеризуется своими специфическими влияниями на социально-культурное и социально-экономическое развитие российских территорий Дальнего Востока. В настоящее время продолжается рост граждан Китая проживающих на приграничных территориях России, что обусловлено привлекательностью условий, созданных благодаря традиционно сложившимся взаимовыгодным отношениям между государствами и народами двух стран. Кроме отмеченного, осуществленное нами исследование позволило установить роль граждан Китая в устойчивом экономическом развитии российских приграничных районов.

\section{ЛИТЕРАТУРА}

1. [俄]翁特尔别格.滨海省（1856-1898） [M].北京：商务印书馆，1980.-C.64-65.

2. 安德鲁·马洛泽诺夫.俄国的远东政策[M].北京: 商务印书馆, 1858.-C.2.

3. 卜君哲.近代俄罗斯西伯利亚及远东地区华侨华人社会研究 (1860-1931) [D]. 长春:东北师范大学硕士学位论文, $2003 .-C .26$.

4. 曹廷杰著: 《西伯利亚东偏纪要》, 载丛佩远等编: 《曹廷杰集》, 中华书局, 1985.-C.72,124.

5. 俄]翁特尔别格.滨海省（1856-1898） [M].北京：商务印书馆，1980-68,75.

6. 黑龙江省地方志编纂委员会. 《黑龙江省志侨务志》对侨居国贡献 [Электронный ресурс]. Режим доступа: http://shuju.zglz.gov.cn/ BookRead.aspx?BookID=201708230054,2020-5-22 (дата обращения: 14.04.2020).

7. 黑龙江省地方志编纂委员会. 《黑龙江省志侨务志》清末民初时期华侨[Электронный ресурс]. Режим доступа: http://shuju.zglz.gov. cn/BookRead.aspx?BookID=201708230054,2020-5-22(дата обращения: 13.05.2020).

8. 黑龙江省地方志编纂委员会. 《黑龙江省志侨务志》清末民初时期华侨[Электронный ресурс]. Режим доступа: http://shuju.zglz.gov. cn/BookRead.aspx?BookID=201708230054,2020-5-22 (дата обращения: 12.04.2020).

9. 宁艳红.旅俄华侨史[M]. 北京: 人民出版社, 2015.-C.18-110.

10. 台湾中央研究研究近代史研究所: 《中俄关系史料: 俄政变与一般交涉》（一）[M].台湾: 中华民国六年. 一.191.

11. 王铁崖.中外旧约章汇编：第一册[M].北京：三联书店，1957-C.145.

12. 总署奏遵义设所管理海参崴俄界华民折》, 《清季外交史料》卷 27 , 光绪八年初八日

(c) Фу Сюецзин (445886690@qq.com), Нин Яньхун (278906744@qq.com).

Журнал «Современная наука: актуальные проблемы теории и практики» 